\title{
Drosophila king tubby (ktub) mediates light- induced rhodopsin endocytosis and retinal degeneration
}

\author{
Shu-Fen Chen, Yu-Chen Tsai and Seng-Sheen Fan ${ }^{*}$
}

\begin{abstract}
Background: The tubby (tub) and tubby-like protein (tulp) genes encode a small family of proteins found in many organisms. Previous studies have shown that TUB and TULP genes in mammalian involve in obesity, neural development, and retinal degeneration. The purpose of this study was to investigate the role of Drosophila king tubby (ktub) in rhodopsin 1 (Rh1) endocytosis and retinal degeneration upon light stimulation.
\end{abstract}

Results: Drosophila ktub mutants were generated using imprecise excision. Wild type and mutant flies were raised in dark or constant light conditions. After a period of light stimulation, retinas were dissected, fixed and stained with anti-Rh1 antibody to reveal Rh1 endocytosis. Confocal and transmission electron microscope were used to examine the retinal degeneration. Immunocytochemical analysis shows that Ktub is expressed in the rhabdomere domain under dark conditions. When flies receive light stimulation, the Ktub translocates from the rhabdomere to the cytoplasm and the nucleus of the photoreceptor cells. Wild type photoreceptors form Rh1-immunopositive large vesicles (RLVs) shortly after light stimulation. In light-induced ktub mutants, the majority of Rh1 remains at the rhabdomere, and only a few RLVs appear in the cytoplasm of photoreceptor cells. Mutation of norpA allele causes massive Rh1 endocytosis in light stimulation. In ktub and norpA double mutants, however, Rh1 endocytosis is blocked under light stimulation. This study also shows that ktub and norpA double mutants rescue the light-induced norpA retinal degeneration. Deletion constructs further demonstrate that the Tubby domain of the Ktub protein participates in an important role in Rh1 endocytosis.

Conclusions: The results in this study delimit the novel function of Ktub in Rh1 endocytosis and retinal degeneration.

Keywords: King-tubby, Rhabdomere, Phototransduction, Endocytosis, Retinal degeneration

\section{Background}

The tubby (tub) and tubby-like protein (tulp) genes encode a small family of proteins found in many organisms, including Drosophila [1], C. elegans [2,3], Gallus [4], Arabidopsis [5] and other plants [6]. Four members of Tubby proteins are in mammals, including TUB, TULP1, TULP2 and TULP3 [7,8]. Mutation in mouse tubby gene leads to photoreceptor and cochlear degeneration and adult-onset obesity [9-11]. Target deletion of tulp1 in mice causes photoreceptor cell degeneration $[12,13]$. Mutation of tulp3 $3^{-/-}$in mice causes defects in neural tube development, increases neuronal apoptosis, and eventually leads to embryonic lethality [14]. Human

\footnotetext{
* Correspondence: sfan@thu.edu.tw

Department of Life Science, Tunghai University, No. 181, Sec. 3, TaichungPort Road, Taichung, R.O.C 407, Taiwan
}

mutations of TULP1 gene result in retinitis pigmentosa, an inherited disease that typically causes retinal degeneration [15-17]. Taken together, these studies suggest an important role of Tub family proteins in retinal development and maintenance. Structural analysis indicates that the C-terminus of TULP proteins are highly conserved, and contain a DNA binding domain. The $\mathrm{N}$-terminus of TULP proteins contain the remnants of the transactivation domains of many transcription factors, suggesting that TULPs may act as transcription factors $[18,19]$. Subsequent studies have shown that TULPs bind to actin and Dynamin-1, suggesting their function in regulating vesicle transport in photoreceptor cells [20,21]. Mutation of tulp1 in mice causes mislocalization of rhodopsin in photoreceptor cells and abnormal formation of 
photoreceptor synapse [22,23]. According to recent studies, Tulps have an extracellular function in which they act as phagocytosis ligands for retinal pigment epithelium $[24,25]$. The role of Tulp as phagocytosis ligand occurs through binding to the MerTK, a TAM receptor tyrosine kinase subfamily [26]. Together, these studies have shown important functions of Tulps in multicellular organisms. However the molecular and cellular functions of tubby family proteins remain obscure. The Drosophila visual system is an excellent model for studying retinal degeneration [27-29]. The Drosophila genome contains one gene, king tubby (ktub), belonging to the tub gene family. Immunocytochemical study has indicated that $k t u b$ is expressed in the developing nervous system, suggesting its role in neural development [1]. Whether ktub participates in retinal degeneration and mediates phototransduction cascade remains unclear. Drosophila photoreceptor cells contain specialized portions of the plasma membrane, called the rhabdomeres. Each rhabdomere consists of numerous tightly packed microvilli, rhodopsin photopigments, and other components of the phototransduction cascade [30-32]. The phototransduction cascade in Drosophila begins with the light activation of rhodopsin (Rh1). Once activated, Rh1 binds to heterotrimeric $G$ protein, which catalyzes the exchange of GDP for GTP on the $G_{\alpha}$ subunit $\left(G_{\alpha q}\right)$. The $\mathrm{G}_{\alpha \mathrm{q}}$ subunit then activates retinal-specific phospholipase $\mathrm{C}$ and causes the opening of the cation-specific channels Trp and Trpl. This eventually leads to the depolarization of the photoreceptor cell and neurotransmitter release. After light activation, rhodopsin kinase and arrestin inactivate the rhodopsin activity [33-35]. Arrestin and AP2 are critical factors for receptor into clathrin mediate endocytosis [36]. Studies in Drosophila have demonstrated that visual arrestin (Arr1) is essential for lightinduced Rh1 internalization [37] and Arr2 is involved in rhodopsin endocytosis under certain pathological situations [38-40].

This article studies how Ktub participates in Drosophila phototransduction and retinal degeneration. Results show that subcellular localization of Ktub in adult photoreceptor cells is light-dependent. In ktub mutant, rhodopsin endocytosis is blocked under light conditions. In addition, retinal degeneration is evident in $k t u b \mathrm{mu}$ tant flies reared in constant light. In norpA mutant, massive endocytotic rhodopsin vesicles appear in the cytoplasm. However, the rhodopsin vesicles appear less in the cytoplasm of norpA and ktub double mutant. To further investigate what domain in Ktub protein is involved in rhodopsin endocytosis, this study uses deletion constructs to examine its ability to mediate endocytosis. Results show that the C-terminal Tubby domain is required for endocytosis. Taken together, these results provide new evidence showing that the Ktub protein is required for mediating rhodopsin endocytosis and retinal degeneration.

\section{Methods}

Drosophila stocks and transgenic constructions

Drosophila melanogaster $w^{1118}$ was used as wild type. Pelement insertion fly, P(GSV6)17325/SM was obtained from the Szeged Drosophila stock center and was used for imprecise excision to isolate $k t u b$ mutants. norp $A^{33}$, Df (2R) ED3791, and rh1-Gal4 were obtained from the Bloomington stock center. All flies were reared on standard corn meal agar media at $25^{\circ} \mathrm{C}$ in dark, $12 \mathrm{D} /$ $12 \mathrm{~L}$ light or constant-light condition. The ambient light used to create light-induced condition was approximately 500 lux. To make transgenic flies that expressed full-length, $\mathrm{N}$-terminus $(\mathrm{N}-\mathrm{ktub})$ and $\mathrm{C}$-terminus $(\mathrm{C}$ $k t u b)$ of Ktub protein, we amplified ktub cDNA by PfuTurbo DNA polymerase from EST clone, RE38560, using the following primers: ktub (5'-ATGTCCGGAATCAA CAGTCGTAATCAG-3', 5'-TCACTC GCAGGCTATTT TGC-3'); $N$ - $k t u b$ (5'-ATGTCCGGAATCAACAGTCGT AATCAG-3, 5'-ATTGCCGATGACATCTCCCTCGGA C-3'); C-ktub (5'-ATCGACCAGTTCGTGATGC AAC-3', 5'-TCACTCGCAGGCTATTTTGC-3'). The PCR fragments were subcloned into pUAST-Flag expression vector [41] to make pUAST-Flag-ktub, pUAST- Flag- N$k t u b$, and $p U A S T-F l a g-C-k t u b$. All constructions were verified by DNA sequencing before germ-line transformation. P-element mediated germ-line transformation [42] produced more than three independent lines. The transgenic lines were crossed to rh1-Gal4 for further analysis.

\section{Generation of ktub mutant fly by P-element imprecise excision}

To generate ktub mutants, we crossed P(GSV6) $17325 / S M$ to a transposase expressing line $(\Delta 2-3)$ to induce P-element excision. After imprecise excision, flies with white eye were crossed to $D f(2 R)$ ED3791 to isolate the ktub /Df (2R) ED3791 adult flies. To identify the mutation site, two primers: 5'-GGCAATTTCAATCGAATTTACC-3' and 5'-ATCGAA GTAACTCGAAGGACCC-3' were used to amplify the 5' region of the ktub gene. A total of 200 P-excision lines were screened to obtain six lines with DNA deletion in the ktub gene. DNA sequence confirmed two alleles, $k t u b^{35-3}$ and $k t u b^{115-4}$, have deleted the ATG translation start site, and these two alleles were used for further analysis.

\section{Antibody production and Western blotting}

To generate antibody against Ktub protein, PCR was used to amplify ktub fragments by two primers: 5'-ATGGAGGCCTACATCCGGCAGAAGAG-3', 
5'-TCACTCGCAGGCTATTT TGCCATCGA- 3'. The PCR products were cloned into $\mathrm{PQE}-31$ vector (Qiagen, Valencia, CA). After IPTG induction, a 56 kDa Ktub recombinant protein was isolated from $E$. coli and used as antigen to inject rabbit. After several boosts, the serum was collected to test its immunoreactivity. For Western blotting, adult eyes were collected and homogenized with a homogenization buffer (50 mM HEPES, $50 \mathrm{mM}$ $\mathrm{KCl}, 1 \mathrm{mM}$ EGTA, $1 \mathrm{mM} \mathrm{MgCl}_{2}, 10 \%$ Glycerol) with protease inhibitors. The cell extract was then centrifuged at $1500 \mathrm{~g}$ for $10 \mathrm{~min}$ at $4^{\circ} \mathrm{C}$ and subjected to SDS-PAGE to separate the protein. SDS-PAGE and Western blotting were performed with slight modification from previous studies [43]. After electrophoresis, the proteins were transferred to a PVDF membrane. To perform immune blotting, the membrane was blocked with $5 \%$ non-fat milk in TBST (10 mM Tris, pH7.4, $150 \mathrm{mM} \mathrm{NaCl}$, with $0.1 \%$ Tween20). The membrane was then incubated with anti-Ktub antiserum (1:2000) at $4^{\circ} \mathrm{C}$ overnight. The following day, the membrane was washed three times with TBST and then incubated with peroxidase conjugated goat anti-rabbit IgG (1:10000). After incubation with the secondary antibody, the membrane was washed and processed for chemiluminescent reaction (Milipore, Billerica MA). The signals were detected with a CCD camera (Fuji film, Japan).

\section{Immunohistochemistry}

To perform immunohistochemical staining, dissected eyes were fixed in $4 \%$ paraformaldehyde for 20 minutes. After three washes and blocking, the eyes were incubated with primary antibody. The primary antibodies used in this study included rabbit anti-Ktub (1:500) and mouse anti-Rh1 (4C5) from Developmental Studies Hybridoma Bank (1:100). Rhodamine or FITC conjugated phalloidin (Sigma-Aldrich, St. Louis, MO), which stained the F-actin, was used to label the cell boundary. Stained eye discs were washed three times with PBST $\left(137 \mathrm{mM} \mathrm{NaCl}, 2.68 \mathrm{mM} \mathrm{KCl}, 10 \mathrm{mM} \mathrm{Na} \mathrm{HPO}_{4}\right.$, $1.7 \mathrm{mM} \mathrm{KH}_{2} \mathrm{PO}_{4}$, pH7.2 with $0.2 \%$ TritonX-100), and then incubated with secondary antibodies. The secondary antibodies used in this study were conjugated with Alex 488 (Invitrogen Molecular Probes, Carlsbad, CA), Texas Red, or Cy5 (Jackson Immuno Research Lab. West Grove, PA). After three washes, eyes were mounted in a mounting medium $(0.25 \% \mathrm{n}$-propyl gallate, $50 \%$ glycerol in PBS, pH 8.6) and examined using a Zeiss LSM 510 confocal microscope. Images were processed using Adobe Photoshop 6.0 software.

\section{Electron microscopy}

Transmission electron microscopy was performed as previously described [44]. Flies were injected with a fixative (2\% paraformaldehyde and $2 \%$ glutaraldehyde in
0.1 M cacodylate buffer). After dissection, the eyes were incubated in fixative for another 2 hours and postfixed with $2 \% \mathrm{OsO}_{4}$ in $0.1 \mathrm{M}$ cacodylate buffer at $4^{\circ} \mathrm{C}$. The eyes were subjected to series dehydration with alcohol and embedded in Epox-812 (EMS). The tissues were then sectioned using a Reichert ultramicrotome and observed using a Tecnai spirit G2 (FEI) transmission electron microscope.

\section{Results}

\section{Isolation of ktub mutants and their phenotypic analysis}

Studies have shown that the mutation of human and mouse tubby family genes results in retinal degeneration, late onset obesity, and cochlear degeneration $[12,13,15,45,46]$. However, the biological functions of tubby genes remain obscure. Using a Basic Local Alignment Search Tool (BLAST) search, we identified Drosophila king-tubby (ktub) gene as a potential homologue of human and mouse Tubby genes. Drosophila ktub is located on chromosome 2R, 57B20-57C2. Genomic annotation indicates $k t u b$ contains two transcripts and two polypeptides. The long and the short forms of Ktub proteins are only 17 amino acids difference in their $\mathrm{N}$ terminus (Additional file 1: Figure S1). This study takes the advantage of Drosophila genetics and uses it to study the cellular functions of Tubby proteins in phototransduction and retinal degeneration. To study the function of $k t u b$, we used imprecise excision to generate ktub deletion mutants from P(GSV6)17325 flies (Figure 1A). Screening approximately $200 \mathrm{P}$-excision lines revealed two mutant alleles $\left(k t u b^{35-3}, k t u b^{115-4}\right)$ whose translational initiation site ATG of long form was deleted (Figure 1B). Western blot analysis showed that Ktub expression in all mutants was significantly reduced, but not completely absent. The remained protein in the Western blot is possibly due to the expression of short form Ktub since our antibody cannot distinguish the long form and the short form of Ktub (Figure 1C). Immunocytochemistry further confirmed the Western blot data, showing that Ktub expression decreased significantly in the adult eyes of ktub mutants (Figure 1D). These results show that we have successfully isolated two ktub mutant alleles, which were used for further functional studies.

\section{The subcellular localization of Ktub in Drosophila eye is light-dependent}

To study the function of Ktub in phototransduction and retinal degeneration, we generated antibodies against Ktub protein. The full length of Ktub recombinant protein was expressed using bacteria, and purified using SDS-PAGE. The purified protein was injected into rabbits to generate anti-Ktub antibody. Western blot analysis revealed that anti-Ktub antibody recognized a band 


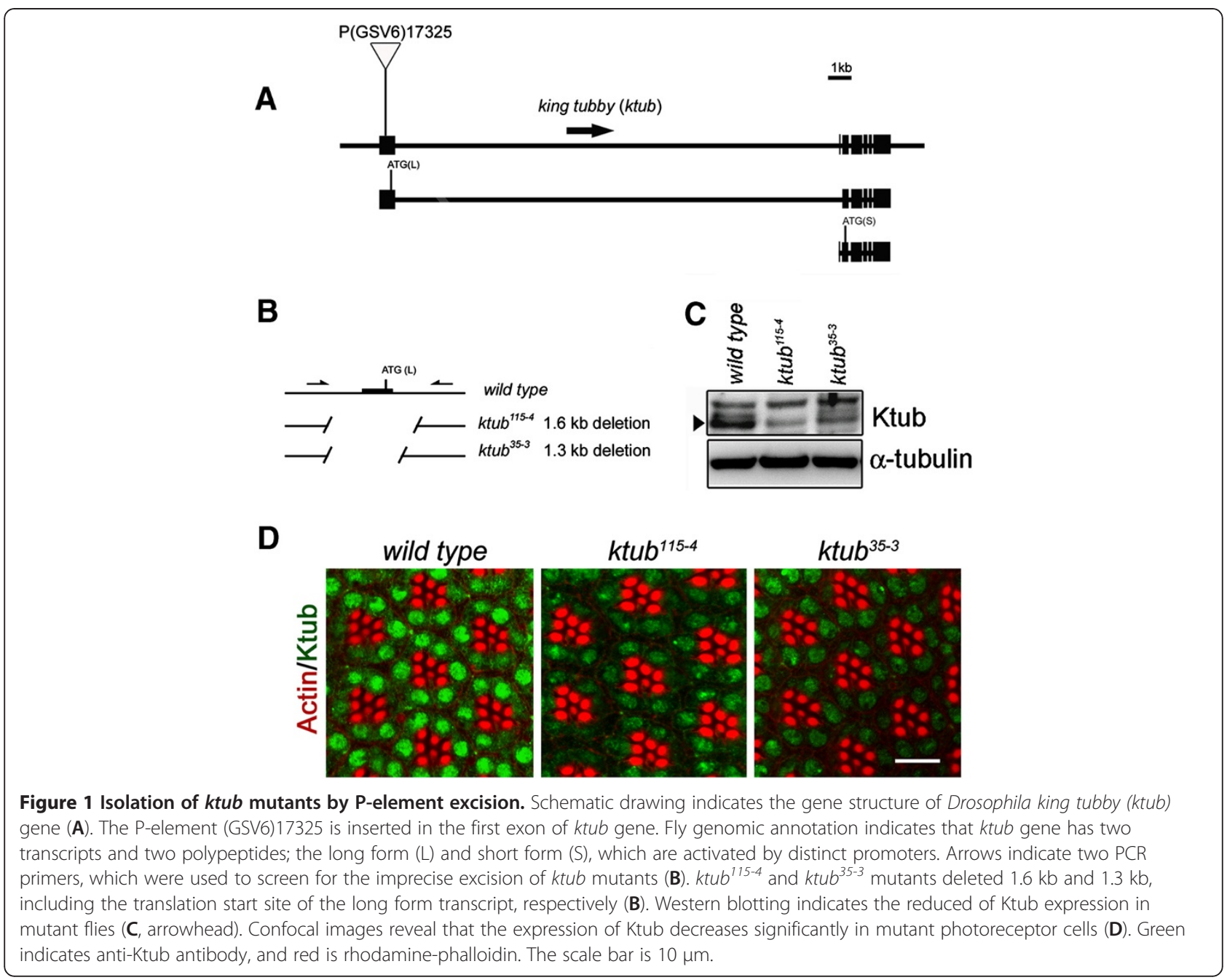

at $50 \mathrm{kDa}$ (Additional file 2: Figure S2A). The $50 \mathrm{kDa}$ band disappeared when anti-Ktub antibody was preincubated with Ktub recombinant protein. These results indicate that the anti-Ktub antibody produced in this experiment is specific to Ktub protein (Additional file 2: Figure S2A). We also used this antibody to probe Drosophila S2 cells. When S2 cells incubated with anti-Ktub antibody, the Ktub protein appeared primarily in the nucleus (Addtional file 2: Figure S2B). When S2 cells were probed with anti-Ktub antibody, which has been preincubated with Ktub recombinant protein, no nuclear signals were detected. This result further indicates the specificity of anti-Ktub antibody generated in this study. To further study the function of Ktub in Drosophila photoreceptor cells, the adult wild type eye was stained with anti-Ktub antibody. When wild type flies were reared in the dark, the Ktub primarily appeared in the rhabdomere domain of photoreceptors R1 to R6 (Figure 2A'). No obvious Ktub signals were detected in the R7 rhabdomere, suggesting its specific function in the photoreceptors R1 to R6. When the dark-reared wild type flies were exposed to light for a few minutes, the rhabdomere localization disappeared, and the Ktub became localized in the cytoplasm instead (Figure 2B'). Under normal 12 hours light/12 hours dark conditions, the Ktub was mainly localized at the nucleus, with some in the cytoplasm of the photoreceptor cells (Figure 2C'). The specific cellular localization of Ktub in the photoreceptor cells between light and dark conditions suggesting its important function in phototransduction.

\section{Knockdown ktub expression resulted in light-dependent retinal degeneration}

Previous studies have found that mutation of mouse tubby caused late-onset and light-dependent retinal degeneration [47]. In this study, we examined whether mutation of Drosophila ktub causes retinal degeneration. To test this hypothesis, we reared wild type and $k t u b$ mutant flies under constant light (500 lux) or dark for 6 days. We dissected and stained the eyes with rhodamine-phalloidin to observe whether loss of ktub leads to retinal degeneration. Confocal images revealed 

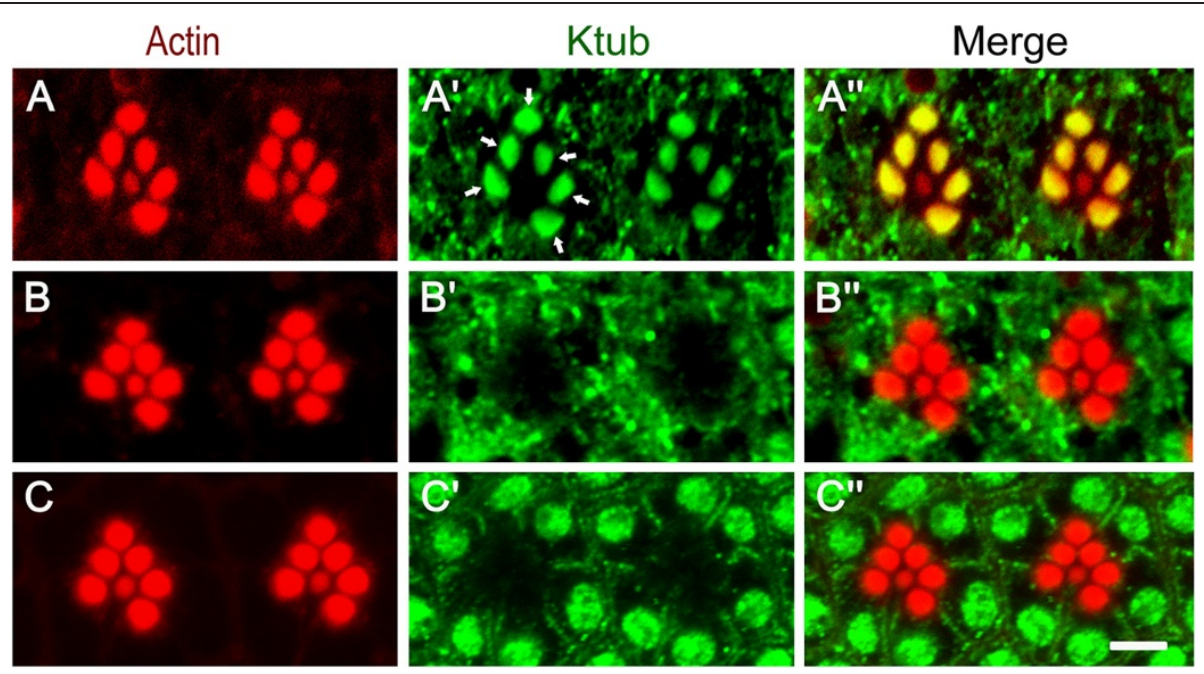

Figure 2 Expression of Ktub in Drosophila photoreceptor cells. Drosophila photoreceptor cells were stained with rhodamine-phalloidin and anti-Ktub antibody. When flies were reared under dark conditions, the majority of Ktub appeared in the rhabdomere domain ( $\mathbf{A}^{\prime}$, arrows). The subcellular localization of Ktub is light sensitive. When flies were removed from the dark and immediately dissected in the light, the Ktub became to localize in the cytoplasm of photoreceptor cells $\left(\mathbf{B}^{\prime}\right)$. When flies were exposed to light (500 lux) for 12 hours, the majority of Ktub appeared in the nucleus with some in the cytoplasm $\left(\mathbf{C}^{\prime}\right)$. A, B and $\mathbf{C}$ were stained with rhodamine-phalloidin (red) $A^{\prime}, B^{\prime}$ and $C^{\prime}$ were stained with anti-Ktub antibody (green). A", B" and $\mathbf{C}^{\prime \prime}$ are merged images. The scale bar is $10 \mu \mathrm{m}$.
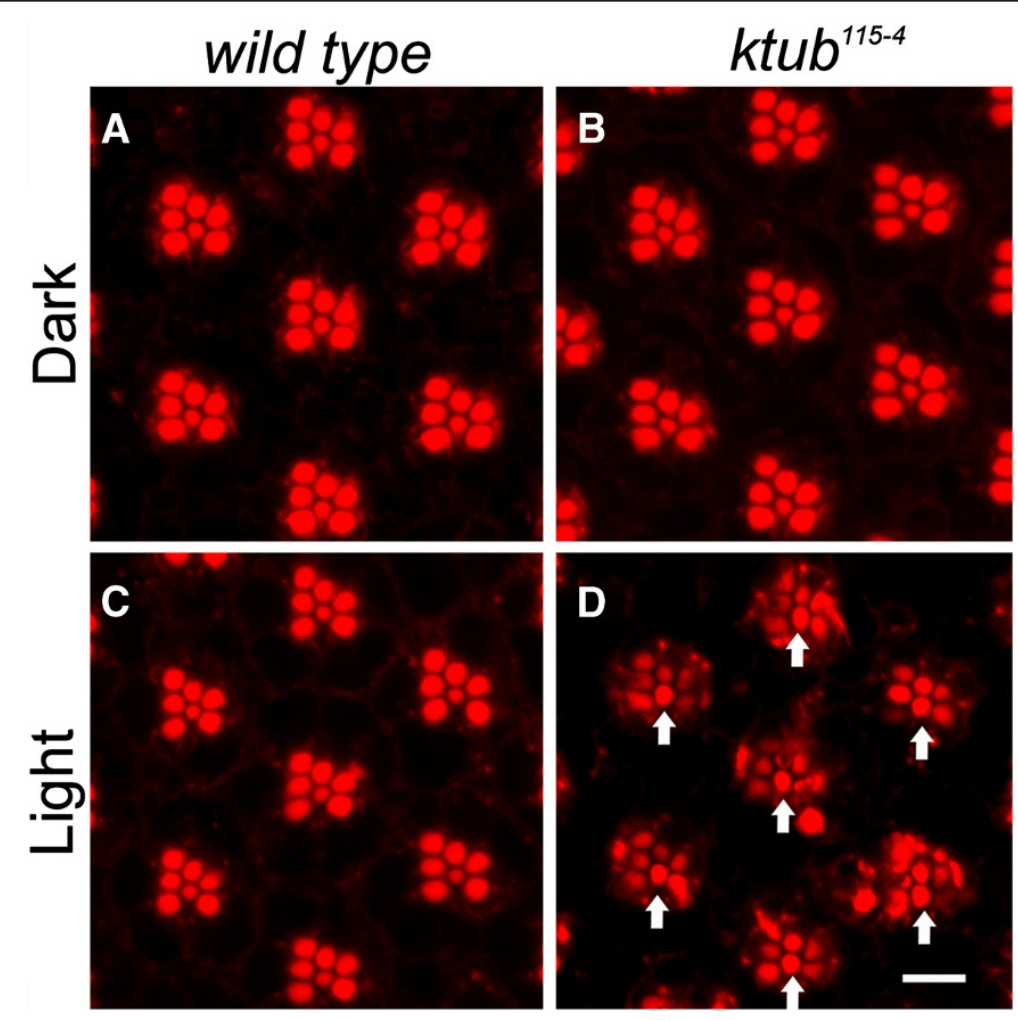

Figure 3 Light-induced retinal degeneration in $k$ tub mutant. Young adults flies $(<1$ day) were reared in the dark $(\mathbf{A}, \mathbf{B})$, or under constant light (500 lux) (C, D) for 6 days. Confocal images indicate that photoreceptor cells arrayed as a typical trapezoid, and the rhabdomere appeared as an oval shape in the wild type and ktub mutant in dark condition (A, C). When flies were reared under constant light for 6 days, wild type photoreceptor cells remained normal (B), but the ktub mutant photoreceptor cells showed significant degeneration (D). The photoreceptor R7 was not affected, and remained as in the wild type (D, arrows). The scale bar is $5 \mu \mathrm{m}$. 
that photoreceptor cells in wild type fly were organized in a typical trapezoid structure for both dark and light conditions (Figure 3A, C). In ktub mutant flies, the rhabdomeres remained intact in flies reared in the dark conditions (Figure 3B). However, the retinal degeneration become evident in photoreceptors R1 to R6 in ktub mutant flies which were reared in light conditions for 6 days (Figure 3D). Generally, the structure of the rhabdomeres appeared loose and lost their integrity when compared to the wild type (Figure 3C, D). The photoreceptor R7 was normal in ktub mutants. This observation is consistent with the expression of Ktub only found in photoreceptors R1 to R6 (Figure 2A'). To further investigate the function of Ktub in retinal degeneration, a transmission electron microscope was used to examine the ultrastructure of the photoreceptor cells in both wild type and $k t u b$ mutant flies. In light-reared conditions, the wild type photoreceptor cells consisted of regular ommatidia arrays. In a tangential section, seven photoreceptor cells were found in an ommatidium. Each photoreceptor cell had a distinguished photosensitive structure, the rhabdomere, which is organized by microvillar structures
(Figure 4A, B). When ktub mutant was reared in light conditions for 6 days, the rhabdomere in photoreceptor R1 to R6 displayed short microvilli and distorted catacomb-like structures at the microvillar base. In addition, we often found that involution of the microvillar membrane into the photoreceptor cell in these mutant cells (Figure 4C, D). These observations suggest that $k t u b$ plays a critical role in maintaining rhabdomere integrity during phototransduction.

\section{Drosophila ktub participates in rhodopsin endocytosis}

Previous research has shown that blocking endocytosis causes intensive retinal degeneration [48]. To determine whether the retinal degeneration in $k t u b$ mutant is caused by the blocking of endocytosis, this study analyzes the Rh1 endocytosis in flies containing a mutation in the $k t u b$ gene. When dark-reared wild type received three hours of light stimulation, a significant amount of the Rh1-immunopositive large vesicles (RLVs) were found in the cytoplasm (Figure 5A). In $k t u b$ mutants, however, the Rh1 was mainly localized in the rhabdomeric domain, and only a few RLVs were found in the
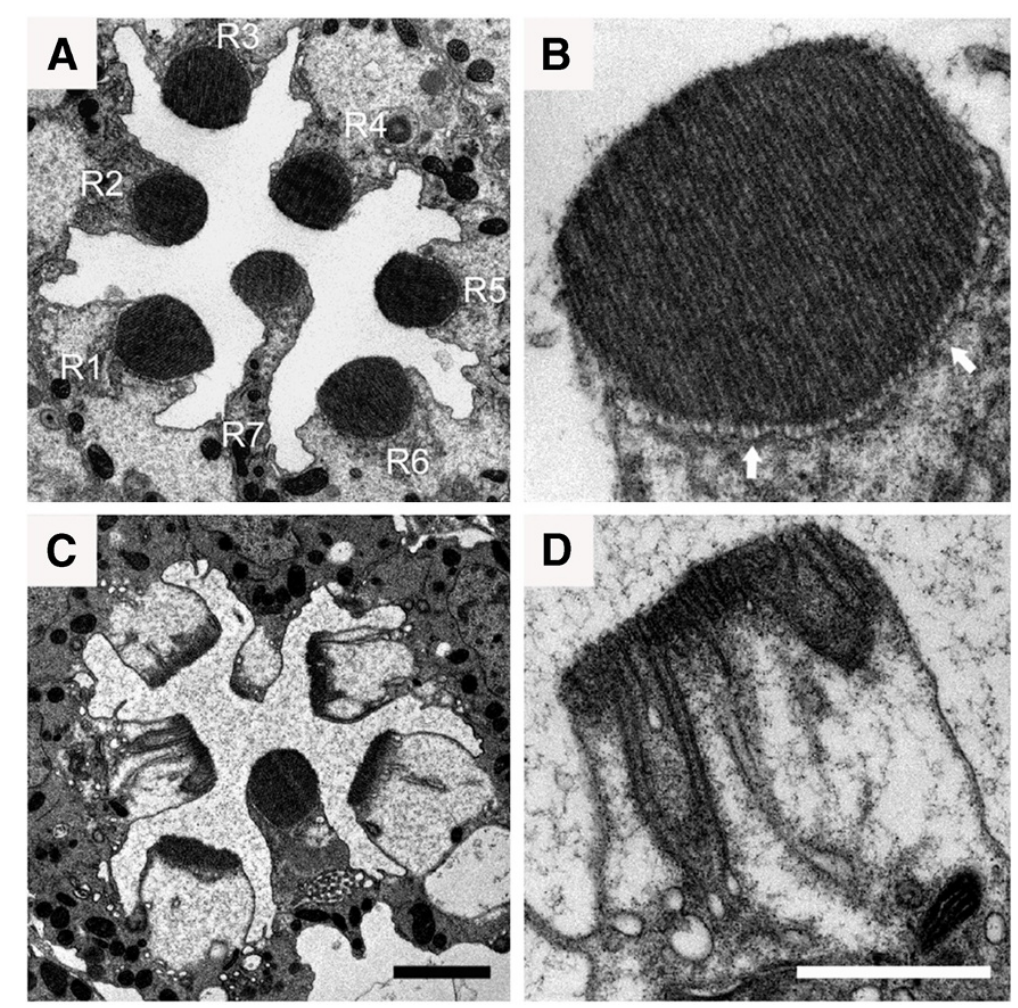

Figure 4 TEM revealed retinal degeneration in ktub mutant. Transmission electron micrographs indicated the photoreceptor cells of wild type and ktub flies raised under constant light for 6 days. Figures show one ommatidium of the wild type (A) and the ktub mutant retina (C). Higher magnification shows single rhabdomere in the wild type (B) and the ktub mutant (D). In the wild type, the rhabdomeres were organized as a regular array of microvilli. The plasma membrane at the base of the rhabdomere appeared as a catacomb-like extracellular space (B, arrows). In the ktub mutant, the rhabdomeres displayed short microvilli, distorted catacomb-like structures at the base, and curtains of microvillar membranes involuting into the photoreceptor cell $(\mathbf{C}, \mathbf{D})$. The photoreceptor R7 as not affected, and remained as in the wild type. The scale bar is $2 \mu \mathrm{m}(\mathbf{A}, \mathbf{C})$ and $1 \mu \mathrm{m}(\mathbf{B}, \mathbf{D})$. 

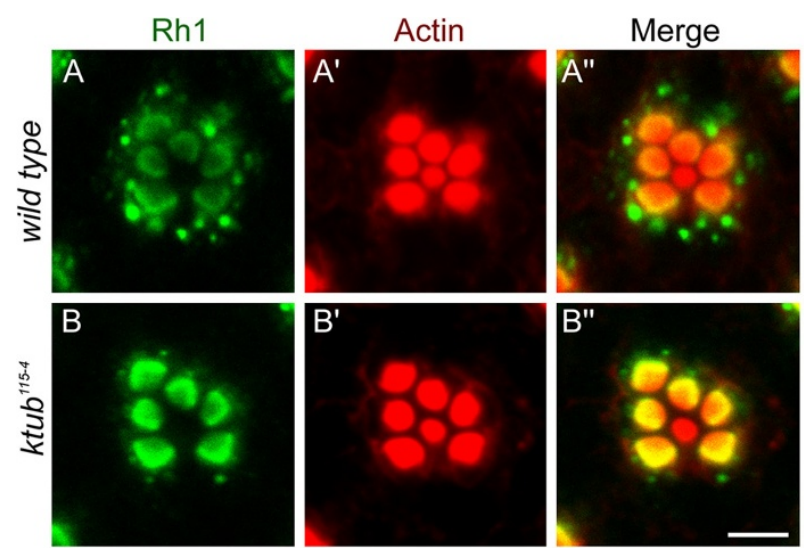

C

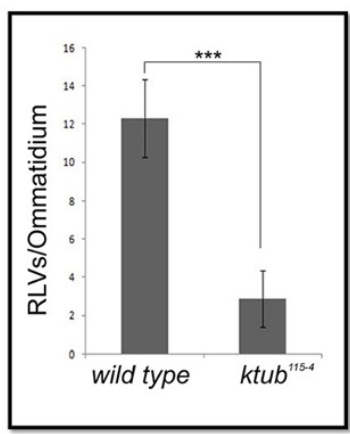

Figure $\mathbf{5}$ ktub participates in light-induced rhodopsin endocytosis. Confocal images reveal rhodopsin localization in the photoreceptor cells of the wild type and ktub mutants. The flies received three hours of light stimulation and then investigated the endocytosis of rhodopsin in the photoreceptor cells. In the wild type (A), a significant amount of RLVs appeared in the cytoplasm of photoreceptor cells. In the ktub mutants (B), the majority of rhodopsin remained in the rhabdomere, with only few RLVs appearing in the cytoplasm of photoreceptor cells. Statistical analysis indicates the number of rhodopsin vesicles in the cytoplasm was significantly different in wild type and ktub mutants (three experiments, Student's t-test *** indicating $p<0.001)$. The scale bar is $10 \mu \mathrm{m}$.
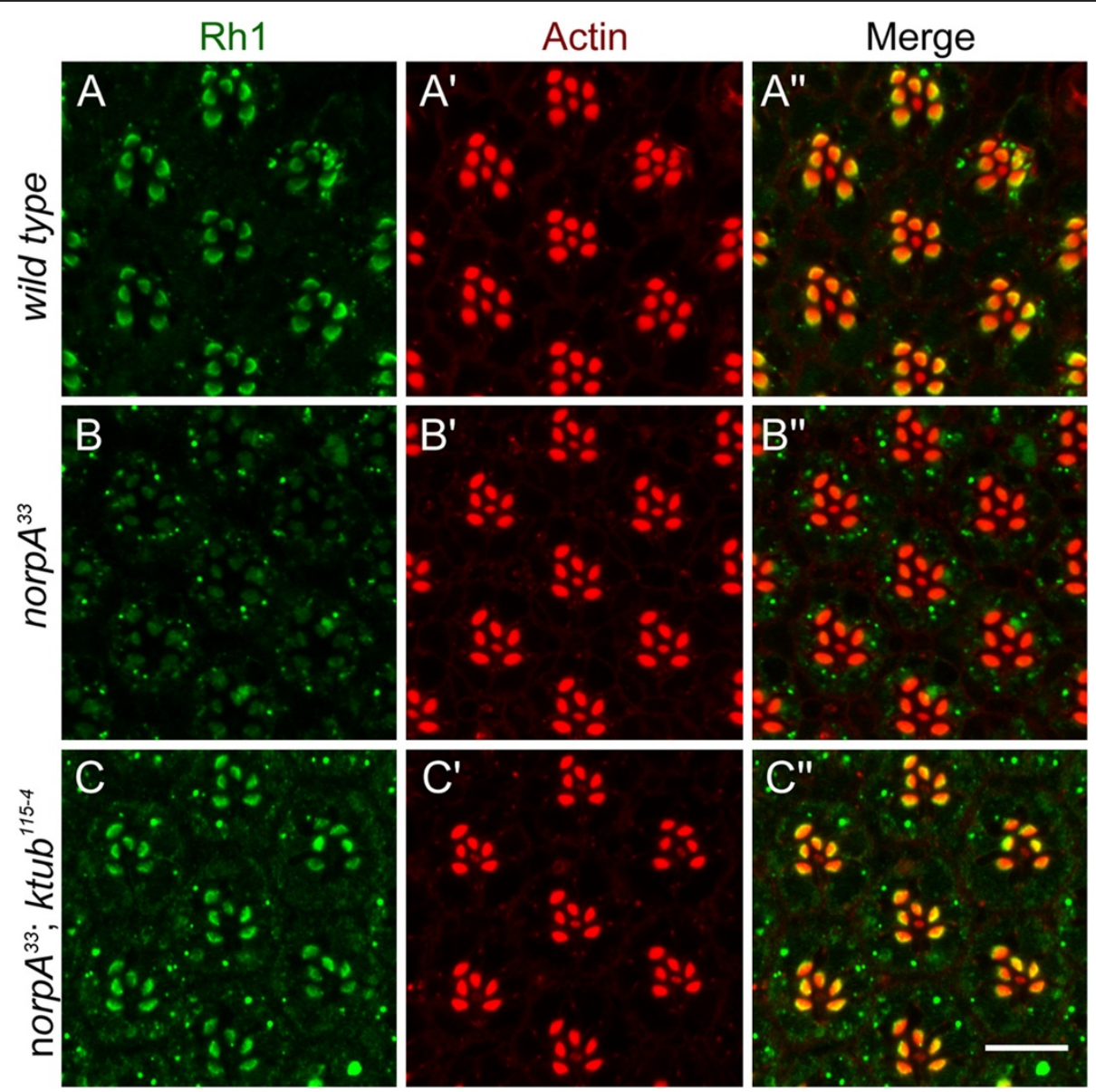

Figure 6 Loss of $k$ tub blocked norpA-mediated rhodopsin endocytosis. Confocal images show the ability of rhodopsin endocytosis in wild type (A), norpA $A^{33}$ (B) and norpA $A^{33} / k_{t u b} b^{175-4}$ double mutants (C). Flies were reared in the dark and then followed by light exposure (500 lux) for 24 hours. After light exposure, some RLVs were detected in the cytoplasm of the wild type photoreceptor cells (A). The norpA $A^{33}$ mutants exhibited massive RLVs in the cytoplasm of photoreceptor cells (B). However, the massive RLVs were rescued by loss of ktub in norpA $A^{33}$ mutants (C). A, B and C were stained with Anti-Rh1antibody (green), and $\mathbf{A}^{\prime}, \mathbf{B}^{\prime}$ and $\mathbf{C}^{\prime}$ were stained with rhodamine-phalloidin (red). 
cytoplasm (Figure 5B). The failure to completely block the Rh1 endocytosis in ktub mutant may be due to the present of short form of Ktub. Quantitative analysis showed the number of RLVs in the wild type and $k t u b$ mutant were significantly different suggesting an important role of $k t u b$ gene in mediating rhodopsin endocytosis (Figure 5C).

\section{$k t u b$ rescues norpA mediated endocytosis and retinal degeneration}

Drosophila norpA is the eye-specific phospholipase C gene. Mutation of norpA causes massive internalization of rhodopsin from rhabdomere to the cell body [49]. To further investigate the role of $k t u b$ in endocytosis, this study examines whether $k t u b$ blocks norp $A$-mediated endocytosis. In wild type flies, the localization of Rh1 occurred mainly in the rhabdomere after 24 hours of light treatment (Figure 6A). In norp $A$ mutants, the majority of rhodopsin disappeared in the rhabdomere, but formed RLVs in the cytoplasm after light stimulation (Figure 6B). In contrast, the majority of Rh1 in the ktub and norp $A$ double mutants remained in the rhabdomere which was same as found in the wild type (Figure $6 \mathrm{C}$ ). To further investigate the role of the ktub on norpA mediated retinal degeneration, wild type and mutant flies were treated with constant-light for 6 days to determine their retinal morphology. The wild type retina contains highly organized ommatidia; each ommatidium contains seven photoreceptor cells in a tangential section. The photosensitive structures, the rhabdomeres faced each other and arranged as a typical trapezoid (Figure 7A). The organization of photoreceptor cells in norpA mutants was severely distorted. Most of the rhabdomeres disappeared after 6 days of light stimulation (Figure 7B). In $k t u b$ and norp $A$ double mutants, the organization of photoreceptor cells was almost same as in the wild type. The rhabdomeres appeared distinct and were arrayed as a typical trapezoid (Figure $7 \mathrm{C}$ ). These observations demonstrate that the norpA mutant phenotype can be rescued by loss-of-function $k t u b$ allele suggesting that an important function of $k t u b$ in mediating rhodopsin endocytosis.

\section{Tubby domain is critical for mediating rhodopsin endocytosis}

To further investigate the molecular mechanism of Ktub protein in endocytotic pathway, transgenic flies expressing different $k t u b$ deletion constructs were prepared to identify the specific protein domain involved in rhodopsin endocytosis. To achieve this goal, we generated three transgenic flies which express the full-length (UAS-Flag-ktub), the N-terminus (UAS- Flag-N-ktub) and the C-terminus (UAS-Flag-C-ktub) of the Ktub protein. Their ability to mediate rhodopsin endocytosis was tested by activating these transgenic flies with the photoreceptor specific driver, the rh1-Gal4. In control experiment, we crossed rh1-Gal4 flies into wild type and found the rhodopsin was mainly localized in the rhabdomere after 3 hours of light activation (Figure 8A). Under the same conditions, the rhodopsin has formed the RLVs and been moved into the cytoplasm of the photoreceptor cells in rh1-Gal4/UAS-Flag-ktub $(r h 1>k t u b)$ flies (Figure $8 \mathrm{~B}$ ). When the $\mathrm{N}$-terminus of Ktub protein was deleted in rh1-Gal4/UAS-Flag-C-ktub $($ rh1 >C-ktub) flies, the RLVs were also found in the cytoplasm, suggesting the endocytosis of rhodopsin into the cytoplasm of the photoreceptor cells (Figure $8 \mathrm{C}$ ). When the Cterminus of Ktub was deleted in rh1-Gal4/UAS-Flag-N$k t u b(r h 1>N-k t u b)$ flies, few RLVs were found in the photoreceptor cells, suggesting the suppression of endocytotic process (Figure $8 \mathrm{D}$ ). These results suggest that the C-terminus Tubby domain is required for mediating rhodopsin endocytosis.

\section{Discussion}

The results of this study demonstrate that Drosophila $k t u b$ plays an important role in mediating Rh1 endocytosis. Immunocytochemical analysis reveals that Ktub is

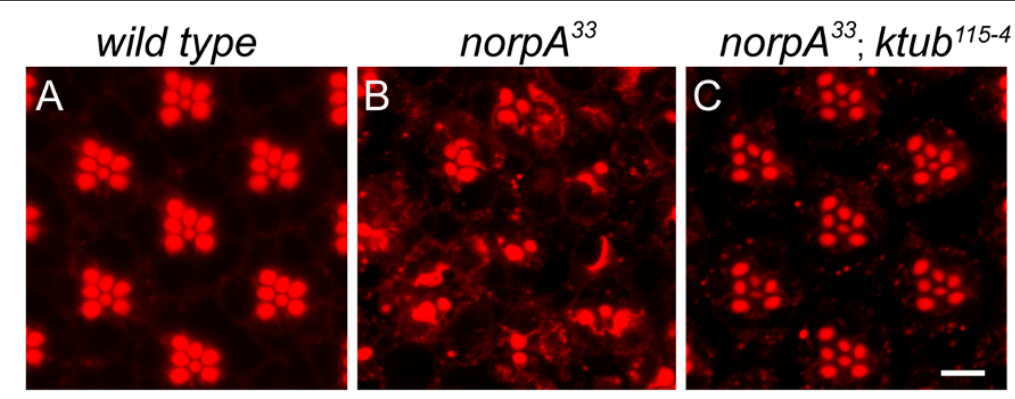

Figure 7 Loss of $k t u b$ blocked norpA-mediated retinal degeneration. Confocal images show photoreceptor cells stained with rhodaminephalloidin in wild type $(\mathbf{A})$, norpA $A^{33}(\mathbf{B})$ and norp $A^{33} / k t u b^{175-4}$ double mutants $(\mathbf{C})$. Wild type photoreceptor cells were arrayed as a typical trapezoid in an ommatidum $(\mathbf{A})$. The majority of photoreceptor cells were degenerated in norp $A^{33}$ mutant $(\mathbf{B})$. In norp $A^{33} / k t u b^{115-4}$ double mutants, the retinal degeneration in norp $A^{33}$ mutant was rescued by loss of ktub gene $(\mathbf{C})$. The scale bar is $10 \mu \mathrm{m}$. 

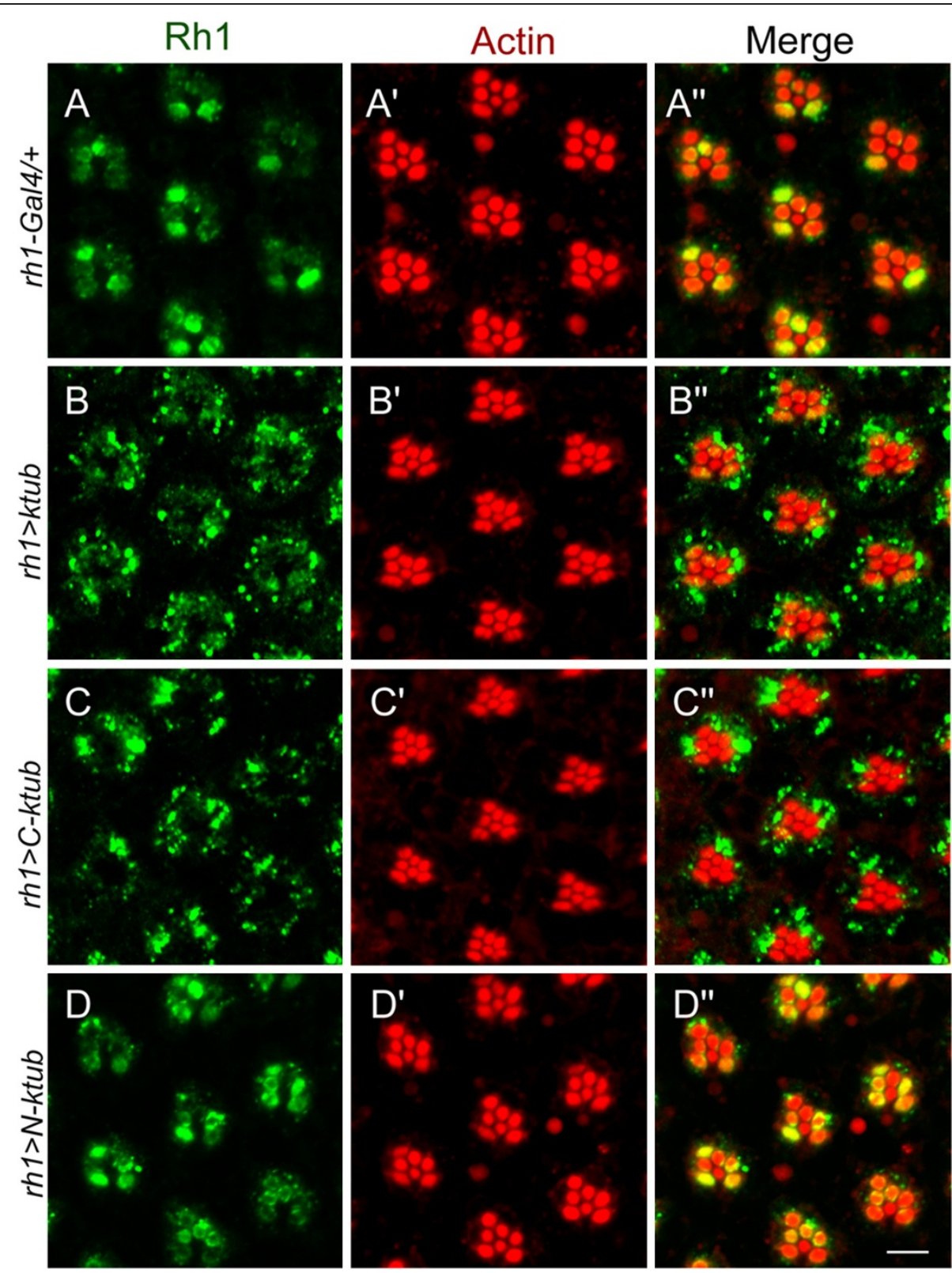

Figure 8 Tubby domain of Ktub is critical for mediating rhodopsin endocytosis. Confocal images show Rh1 endocytosis in photoreceptor cells. Flies received light stimulation for three hours and then processed for immunostaining with anti-Rh1 antibody and rhodamine-phalloidin. In wild type (A), some RLVs appeared in the cytoplasm of photoreceptor cells. In $r h 1>$ ktub flies, massive RLVs appeared in the cytoplasm of photoreceptor cells (B). rhl > C-ktub flies, many RLVs appeared in the cytoplasm of photoreceptor cells (C). In rhl > N-ktub flies, only a few RLVs appeared in the cytoplasm of photoreceptor cells (D). The scale bar is $10 \mu \mathrm{m}$.

primarily located in the rhabdomeric domain in the dark. When the eye was exposed to light, the Ktub protein was immediately translocalized from the rhabdomere to the cytoplasm of the photoreceptor cells. This study further demonstrated that the subcellular expression pattern of the Ktub is correlated with Rh1 expression, which is also internalized upon light stimulation. The correlation of Ktub and Rh1 expression in photoreceptor cells suggests that these two molecules play similar roles during phototransduction. To determine whether Ktub regulates Rh1 internalization, we generated ktub mutants and assayed the role of Ktub in Rh1 endocytosis. Light-reared $k t u b$ mutant flies had significantly fewer RLVs in the cytoplasm of the photoreceptor than the wild type. In addition, light-stimulated $k t u b$ mutant flies also exhibited a severe retinal degeneration phenotype. To further demonstrate the role of ktub in endocytosis, we examined its ability to suppress norpA- 
mediated endocytosis. Results clearly demonstrate that $k t u b$ mutant blocked norpA-mediated endocytosis and retinal degeneration. Previous research has intensively studied the functions of Tub proteins in vertebrate systems. Several studies have shown that Tub and Tulp proteins are involved in retinal degeneration, obesity, and protein trafficking [19]. Studies also show that retinal degeneration in tubby mice is regulated by caspase3 mediated pathway [47]. Currently, we do not know whether the retinal degeneration in ktub mutant is mediated by caspase- 3 mediated pathway. However, previous studies show that the retinal degeneration in norpA mutant is not regulated by caspase mediated pathway [50]. The results in this study find that ktub mutant could rescue norpA mutant phenotype suggesting that the retinal degeneration in $k t u b$ mutant is not through caspase mediated pathway. Thus, it will be interested to study the molecular mechanism of Ktub in mediated retinal degeneration. This study shows that Ktub protein was mainly localized in the rhabdomeric microvilli of dark-reared flies (Figure 2). When flies were exposed to the light, the Ktub proteins translocated from the rhabdomere to the cytoplasm of the photoreceptor cells, suggesting that the function of Ktub is lightdependent (Figure 2). In Drosophila eyes, the photosensitive protein $\mathrm{Rh} 1$ is localized in the rhabdomeric microvilli in dark-reared flies. When flies receive light stimulation, rhodopsin kinase phosphorylates the Rh1 at its C-terminus [51,52] and then internalizes into the cytoplasm of the photoreceptor cells (Figure 5 and [38] ). Arrestin 1 and arrestin 2 are required for Rh1 endocytosis upon light stimulation [37,53]. In the arrestins mutant, Rh1 remains in the active stage in the phototransduction cascade. The consequence of active Rh1 accumulation causes photoreceptor cells to undergo light-dependent retinal degeneration [54]. Previous studies have revealed massive Rh1 endocytosis in norp $A$ mutants, and that the Rh1 endocytosis in norpA mutant is blocked by the $s h i^{t s}$ mutant allele $[38,55]$. The current study reveals that the formation of RLVs in ktub mutant is less than that in wild type upon light stimulation (Figure 5). The ktub/norpA double mutant also suppressed Rh1 endocytosis and retinal degeneration, further supporting that Ktub regulates Rh1 endocytosis (Figure 6). In mice, Dynamin-1 is colocalized with TULP1 in the outer plexiform layer and the inner segments of retina [21]. Biochemical analysis demonstrates that Dynamin-1 binds directly to TULP1[21]. Dynamin1 is a major component of vesicle formation in receptor mediated endocytosis, synaptic vesicle recycling, and vesicle trafficking in and out of the trans-Golgi network [56-58]. This study shows that Ktub has a similar function to Dynamin-1 in blocking norpA-mediated massive Rh1 endocytosis. Although this study does not provide evidence showing a direct interaction between Ktub and Drosophila Dynamin, the idea that Ktub may bind to Drosophila Dynamin is consistent with the observation that Tub protein binds to Dynamin and regulates vesicle transport in mice [21]. In addition, the TUB-1 protein in C. elegans controls fat storage through the RAB-7 mediated endocytosis pathway [3]. Previous studies support the function of Ktub in mediating the endocytotic pathway. Further research should test whether Ktub also binds to Dynamin or whether it mediates the endocytotic pathway through Rab-7.

To determine which domain of Ktub protein is involved in endocytosis, this study uses Ktub deletion constructions in which either the $\mathrm{N}$-terminus or Cterminus of Ktub protein was deleted. This study also tests which constructs failed to mediate Rh1 endocytosis in photoreceptor cells. Results show that the deletion of the C-terminus in the Ktub protein blocked lightinduced Rh1 endocytosis (Figure 8). Structural analysis indicates that the Tubby $\mathrm{C}$-terminal domain binds to double strand DNA and its $\mathrm{N}$-terminal domain activates transcription [18]. Previous studies have also shown an unconventional secretion of Tubby and Tulp1, indicating that they function as phagocytosis ligands for retinal pigment epithelium and macrophage phagocytosis [24,25]. Further investigation reveals that Tubby and Tulp1 act as bridging molecules, as their $\mathrm{N}$-terminal region functions as an MreTK- binding domain and the C-terminal region functions as a phagocytosis prey-binding domain [26]. This study shows that the deletion of the Ktub Cterminus blocked Rh1 endocytosis, suggesting that the C-terminus may contain an important domain for mediating endocytosis. It is worth further investigation which specific peptide sequence is involved in mediating endocytosis. Because of the large fragment of deletion, it cannot be ruled out the possibility that the results from the deletion constructs are not physiological. Although the role of the C-terminus of Ktub protein in endocytosis is not completely clear, this study provides valuable information to further investigate the function of Ktub in endocytosis. Taken together, this study provides substantial support for the function of Drosophila ktub in mediating Rh1 endocytosis and retinal degeneration under light-dependent conditions.

\section{Conclusions}

This study examined the function of Drosophila ktub gene in phototransduction. Immunocytochemical studies showed the subcellular localization of Ktub in photoreceptor cells is light-dependent. In $k t u b$ mutants, the rhodopsin endocytosis is blocked under light stimulation. We also observed a retinal degeneration phenotype in ktub mutants. Using deletion constructs, we found the $\mathrm{C}$-terminus of Ktub is required for Rh1 endocytosis. 
Taken together, these results delimit the novel function of Ktub in Rh1 endoytosis and retinal degeneration.

\section{Additional files}

Additional file 1: Figure S1. Sequence alignments ofDrosophila Ktublong (Ktub-L) form and short (Ktub-S) form. Two peptide sequences were aligned using Expasy. The peptide sequence between long form and short form match perfectly with the exception of an additional 17 amino acids in the $\mathrm{N}$-terminus of the long form protein. The blue line indicates the Tubby domain.

Additional file 2: Figure S2. Determining the specificity of anti-Ktub antibody. Western blot analysis reveals that anti-Ktub antibody recognizes a $50 \mathrm{kDa}$ protein ( $\mathrm{A}$, arrow). When antibody was preincubated with Ktub recombinant protein, the $50 \mathrm{kDa}$ band disappeared (A). Confocal images show Ktub expression in the Drosophila S2 cells (B). When Drosophila S2 cells were probed with anti-Ktub antibody, the antibody detected a nuclear signal in the $\mathrm{S} 2$ cells. The nuclear signal disappeared when antibody was preincubated with Ktub recombinant protein. Propidium iodide (PI) stains for nucleus (red). The scale bar is $10 \mu \mathrm{m}$.

\section{Competing interests}

The authors declare that they have no competing interests.

\section{Authors' contributions}

SFC, YCT and SSF designed the experiments. SFC performed the genetic screening and all the experiments. YCT helped the genetic experiment. SSF wrote the manuscript. All authors read and approved the final manuscript.

\section{Acknowledgements}

The authors thank Bloomington Stock Center, Szeged Drosophila Stock Center, and the Developmental Studies Hybridoma Bank for stocks and antibodies. We also thank H. Sun, C. Y. Tang, and C. P. Hu for their assistance in microinjection and antibody production respectively. This study was supported by the National Science Council, Taiwan, Republic of China for SSF (NSC 98-2311-B-029-002-MY3 and NSC 99-2632-B-029-001-MY3).

Received: 4 November 2012 Accepted: 4 December 2012 Published: 10 December 2012

\section{References}

1. Ronshaugen M, McGinnis N, Inglis D, Chou D, Zhao J, McGinnis W: Structure and expression patterns of Drosophila TULP and TUSP, members of the tubby-like gene family. Mech Dev 2002, 117:209-215.

2. Ashrafi K, Chang FY, Watts JL, Fraser AG, Kamath RS, Ahringer J, Ruvkun G: Genome-wide RNAi analysis of Caenorhabditis elegans fat regulatory genes. Nature 2003, 421:268-272.

3. Mukhopadhyay A, Pan X, Lambright DG, Tissenbaum HA: An endocytic pathway as a target of tubby for regulation of fat storage. EMBO Rep 2007, 8:931-938.

4. Heikenwalder MF, Koritschoner NP, Pajer P, Chaboissier MC, Kurz SM, Briegel $\mathrm{KJ}$, Bartunek P, Zenke M: Molecular cloning, expression and regulation of the avian tubby-like protein 1 (tulp1) gene. Gene 2001, 273:131-139.

5. Lai CP, Lee CL, Chen PH, Wu SH, Yang CC, Shaw JF: Molecular analyses of the Arabidopsis TUBBY-like protein gene family. Plant Physio/ 2004, 134:1586-1597.

6. Yang Z, Zhou Y, Wang X, Gu S, Yu J, Liang G, Yan C, Xu C: Genomewide comparative phylogenetic and molecular evolutionary analysis of tubby-like protein family in Arabidopsis, rice, and poplar. Genomics 2008, 92:246-253.

7. North MA, Naggert JK, Yan Y, Noben-Trauth K, Nishina PM: Molecular characterization of TUB, TULP1, and TULP2, members of the novel tubby gene family and their possible relation to ocular diseases. Proc Natl Acad Sci USA 1997, 94:3128-3133.

8. Nishina PM, North MA, Ikeda A, Yan Y, Naggert JK: Molecular characterization of a novel tubby gene family member, TULP3, in mouse and humans. Genomics 1998, 54:215-220.
9. Kleyn PW, Fan W, Kovats SG, Lee JJ, Pulido JC, Wu Y, Berkemeier LR, Misumi DJ, Holmgren L, Charlat O, Woolf EA, Tayber O, Brody T, Shu P, Hawkins F, Kennedy B, Baldini L, Ebeling C, Alperin GD, Deeds J, Lakey ND, Culpepper J, Chen H, Glucksmann-Kuis MA, Carlson GA, Duyk GM, Moore KJ: Identification and characterization of the mouse obesity gene tubby: a member of a novel gene family. Cell 1996, 85:281-290.

10. Noben-Trauth K, Naggert JK, North MA, Nishina PM: A candidate gene for the mouse mutation tubby. Nature 1996, 380:534-538.

11. Ohlemiller KK, Hughes RM, Mosinger-Ogilvie J, Speck JD, Grosof DH, Silverman MS: Cochlear and retinal degeneration in the tubby mouse. Neuroreport 1995, 6:845-849.

12. Hagstrom SA, Duyao M, North MA, Li T: Retinal degeneration in tulp1-/mice: vesicular accumulation in the interphotoreceptor matrix. Invest Ophthalmol Vis Sci 1999, 40:2795-2802.

13. Ikeda S, Shiva N, Ikeda A, Smith RS, Nusinowitz S, Yan G, Lin TR, Chu S, Heckenlively JR, North MA, Naggert JK, Nishina PM, Duyao MP: Retinal degeneration but not obesity is observed in null mutants of the tubbylike protein 1 gene. Hum Mol Genet 2000, 9:155-163.

14. Ikeda A, Ikeda S, Gridley T, Nishina PM, Naggert JK: Neural tube defects and neuroepithelial cell death in Tulp3 knockout mice. Hum Mol Genet 2001, 10:1325-1334.

15. Hagstrom SA, North MA, Nishina PL, Berson EL, Dryja TP: Recessive mutations in the gene encoding the tubby-like protein TULP1 in patients with retinitis pigmentosa. Nat Genet 1998, 18:174-176

16. Gu S, Lennon A, Li Y, Lorenz B, Fossarello M, North M, Gal A, Wright A: Tubby-like protein-1 mutations in autosomal recessive retinitis pigmentosa. Lancet 1998, 351:1103-1104.

17. Banerjee P, Kleyn PW, Knowles JA, Lewis CA, Ross BM, Parano E, Kovats SG, Lee JJ, Penchaszadeh GK, Ott J, Jacobson SG, Gilliam TC: TULP1 mutation in two extended Dominican kindreds with autosomal recessive retinitis pigmentosa. Nat Genet 1998, 18:177-179.

18. Boggon TJ, Shan WS, Santagata S, Myers SC, Shapiro L: Implication of tubby proteins as transcription factors by structure-based functional analysis. Science 1999, 286:2119-2125.

19. Carroll K, Gomez C, Shapiro L: Tubby proteins: the plot thickens. Nat Rev Mol Cell Biol 2004, 5:55-63.

20. Xi Q, Pauer GJ, Marmorstein AD, Crabb JW, Hagstrom SA: Tubby-like protein 1 (TULP1) interacts with F-actin in photoreceptor cells. Invest Ophthalmol Vis Sci 2005, 46:4754-4761.

21. Xi Q, Pauer GJ, Ball SL, Rayborn M, Hollyfield JG, Peachey NS, Crabb JW, Hagstrom SA: Interaction between the photoreceptor-specific tubby-like protein 1 and the neuronal-specific GTPase dynamin-1. Invest Ophthalmol Vis Sci 2007, 48:2837-2844.

22. Hagstrom SA, Adamian M, Scimeca M, Pawlyk BS, Yue G, Li T: A role for the Tubby-like protein 1 in rhodopsin transport. Invest Ophthalmol Vis Sci 2001, 42:1955-1962.

23. Grossman GH, Pauer GJ, Narendra U, Peachey NS, Hagstrom SA: Early synaptic defects in tulp1-/- mice. Invest Ophthalmol Vis Sci 2009, 50:3074-3083

24. Caberoy NB, Li W: Unconventional secretion of tubby and tubby-like protein 1. FEBS Lett 2009, 583:3057-3062.

25. Caberoy NB, Maiguel D, Kim Y, Li W: Identification of tubby and tubby-like protein 1 as eat-me signals by phage display. Exp Cell Res 2010, 316:245-257.

26. Caberoy NB, Zhou Y, Li W: Tubby and tubby-like protein 1 are new MerTK ligands for phagocytosis. EMBO J 2010, 29:3898-3910.

27. Montell C: Visual transduction in Drosophila. Annu Rev Cell Dev Biol 1999, 15:231-268.

28. Zuker CS: The biology of vision of Drosophila. Proc Natl Acad Sci USA 1996, 93:571-576.

29. Shieh BH: Molecular genetics of retinal degeneration: a Drosophila perspective. Fly (Austin) 2011, 5:356-368.

30. Montell C, Rubin GM: Molecular characterization of the Drosophila trp locus: a putative integral membrane protein required for phototransduction. Neuron 1989, 2:1313-1323.

31. Van Vactor D, O'Reilly AM, Neel BG: Genetic analysis of protein tyrosine phosphatases. Curr Opin Genet Dev 1998, 8:112-126.

32. Kumar JP, Ready DF: Rhodopsin plays an essential structural role in Drosophila photoreceptor development. Development 1995, 121:4359-4370. 
33. Bennett N, Sitaramayya A: Inactivation of photoexcited rhodopsin in retinal rods: the roles of rhodopsin kinase and 48-kDa protein (arrestin). Biochemistry 1988, 27:1710-1715.

34. Kuhn $\mathrm{H}$, Wilden $\mathrm{U}$ : Deactivation of photoactivated rhodopsin by rhodopsin-kinase and arrestin. J Recept Res 1987, 7:283-298.

35. Hardie RC, Raghu P: Visual transduction in Drosophila. Nature 2001 413:186-1893

36. Laporte SA, Oakley RH, Holt JA, Barak LS, Caron MG: The interaction of beta-arrestin with the AP-2 adaptor is required for the clustering of beta 2-adrenergic receptor into clathrin-coated pits. J Biol Chem 2000, 275:23120-23126.

37. Satoh AK, Ready DF: Arrestin1 mediates light-dependent rhodopsin endocytosis and cell survival. Curr Biol 2005, 15:1722-1733.

38. Alloway PG, Howard L, Dolph PJ: The formation of stable rhodopsinarrestin complexes induces apoptosis and photoreceptor cell degeneration. Neuron 2000, 28:129-138.

39. Kiselev A, Socolich M, Vinos J, Hardy RW, Zuker CS, Ranganathan R: A molecular pathway for light-dependent photoreceptor apoptosis in Drosophila. Neuron 2000, 28:139-152.

40. Lee SJ, Xu H, Kang LW, Amzel LM, Montell C: Light adaptation through phosphoinositide-regulated translocation of Drosophila visual arrestin. Neuron 2003, 39:121-132.

41. Yao JG, Sun YH: Eyg and Ey Pax proteins act by distinct transcriptional mechanisms in Drosophila development. EMBO J 2005, 24:2602-2612.

42. Spradling AC, Rubin GM: Transposition of cloned P elements into Drosophila germ line chromosomes. Science 1982, 218:341-347.

43. Towbin H, Staehelin T, Gordon J: Electrophoretic transfer of proteins from polyacrylamide gels to nitrocellulose sheets: procedure and some applications. Proc Natl Acad Sci USA 1979, 76:4350-4354.

44. Fan SS: Dynactin affects extension and assembly of adherens junctions in Drosophila photoreceptor development. J Biomed Sci 2004, 11:362-369.

45. Lewis CA, Batlle IR, Batlle KG, Banerjee P, Cideciyan AV, Huang J, Aleman TS, Huang Y, Ott J, Gilliam TC, Knowles JA, Jacobson SG: Tubby-like protein 1 homozygous splice-site mutation causes early-onset severe retinal degeneration. Invest Ophthalmol Vis Sci 1999, 40:2106-2114.

46. Ikeda A, Zheng QY, Rosenstiel P, Maddatu T, Zuberi AR, Roopenian DC, North MA, Naggert JK, Johnson KR, Nishina PM: Genetic modification of hearing in tubby mice: evidence for the existence of a major gene (moth1) which protects tubby mice from hearing loss. Hum Mol Genet 1999, 8:1761-1767.

47. Kong L, Li F, Soleman CE, Li S, Elias RV, Zhou X, Lewis DA, McGinnis JF, Cao W: Bright cyclic light accelerates photoreceptor cell degeneration in tubby mice. Neurobiol Dis 2006, 21:468-477.

48. Acharya U, Patel S, Koundakjian E, Nagashima K, Han X, Acharya JK: Modulating sphingolipid biosynthetic pathway rescues photoreceptor degeneration. Science 2003, 299:1740-1743.

49. Orem NR, Dolph PJ: Epitope masking of rhabdomeric rhodopsin during endocytosis-induced retinal degeneration. Mol Vis 2002, 8:455-461.

50. Hsu CD, Whaley MA, Frazer K, Miller DA, Mitchell KA, Adams SM, O'Tousa JE: Limited role of developmental programmed cell death pathways in Drosophila norpA retinal degeneration. J Neurosci 2004, 24:500-507.

51. Vinos J, Jalink K, Hardy RW, Britt SG, Zuker CS: A G protein-coupled receptor phosphatase required for rhodopsin function. Science 1997, 277:687-690.

52. Lee SJ, Xu H, Montell C: Rhodopsin kinase activity modulates the amplitude of the visual response in Drosophila. Proc Natl Acad Sci USA 2004, 101:11874-11879.

53. Orem NR, Xia L, Dolph PJ: An essential role for endocytosis of rhodopsin through interaction of visual arrestin with the AP-2 adaptor. J Cell Sci 2006, 119:3141-3148.

54. Dolph PJ, Ranganathan R, Colley NJ, Hardy RW, Socolich M, Zuker CS: Arrestin function in inactivation of $\mathrm{G}$ protein-coupled receptor rhodopsin in vivo. Science 1993, 260:1910-1916.

55. Orem NR, Dolph PJ: Loss of the phospholipase $C$ gene product induces massive endocytosis of rhodopsin and arrestin in Drosophila photoreceptors. Vision Res 2002, 42:497-505.

56. Van der Bliek AM: Functional diversity in the dynamin family. Trends Cell Biol 1999, 9:96-102.

57. McNiven MA, Kim L, Krueger EW, Orth JD, Cao H, Wong TW: Regulated interactions between dynamin and the actin-binding protein cortactin modulate cell shape. J Cell Biol 2000, 151:187-198.
58. Tomizawa K, Sunada S, Lu YF, Oda Y, Kinuta M, Ohshima T, Saito T, Wei FY, Matsushita M, Li ST, Tsutsui K, Hisanaga S, Mikoshiba K, Takei K, Matsui H: Cophosphorylation of amphiphysin I and dynamin I by $\mathrm{Cdk} 5$ regulates clathrin-mediated endocytosis of synaptic vesicles. J Cell Biol 2003, 163:813-824.

\section{doi:10.1186/1423-0127-19-101}

Cite this article as: Chen et al:: Drosophila king tubby (ktub) mediates light-induced rhodopsin endocytosis and retinal degeneration. Journal of Biomedical Science 2012 19:101.

\section{Submit your next manuscript to BioMed Central and take full advantage of:}

- Convenient online submission

- Thorough peer review

- No space constraints or color figure charges

- Immediate publication on acceptance

- Inclusion in PubMed, CAS, Scopus and Google Scholar

- Research which is freely available for redistribution

Submit your manuscript at www.biomedcentral.com/submit
C Biomed Central 